\title{
PERCEPÇÃO DOS MORADORES DE CANANÉIA - SP SOBRE A ARBORIZAÇÃO URBANA DO MUNICÍPIO
}

\author{
RESIDENTS' PERCEPTION OF CANANÉIA-SP REGARDING THE URBAN \\ AFFORESTATION OF THE MUNICIPALITY
}

\author{
Ana Paula de Souza Maistro ${ }^{1}$, Marcelo Vieira Ferraz ${ }^{2}$
}

\section{RESUMO}

A percepção ambiental objetiva investigar a maneira como o homem enxerga, interpreta, convive e se adapta à realidade do meio em que vive. O presente trabalho teve como objetivo realizar a avaliação do dos moradores com relação a arborização urbana de Cananéia - SP, de modo a avaliar o grau de conscientização ambiental e a percepção dos moradores com relação as árvores para se obter informações acerca das necessidades, críticas e sugestões dos munícipes para colaborar na elaboração de futuros planos de gestão. Para isso foram aplicados dez questionários previamente elaborados em cada bairro do município, totalizando oitenta questionários aplicados. Os resultados indicaram que a $50,0 \%$ dos entrevistados classificaram a arborização urbana como "razoável", 47,5\% indicaram a produção de sombra como vantagem da arborização, e 33,6\% indicaram como desvantagem os problemas rede elétrica ou telefonia.

Palavras-chave: Planejamento; Avaliação; Benefícios.

\begin{abstract}
Environmental perception aims to investigate how man sees, interprets, lives and adapts to the reality of the environment they live in. The present study aimed to diagnose the perception of residents regarding urban afforestation of Cananéia - SP, in order to assess the level of environmental awareness and information about the needs, criticisms and suggestions of citizens to collaborate on future management plans. For this, ten questionnaires previously prepared in each neighborhood of the municipality were applied, totaling eighty questionnaires applied. The results indicated that $50.0 \%$ of respondents rated the urban trees as "reasonable", $47.5 \%$ indicated the advantage of forestation, production of shadow and $33.6 \%$ as a disadvantage the electrical or telephone network problems.
\end{abstract}

Keywords: Planning; Evaluation; Benefits.

Recebido em 03.07.2017 e aceito em 15.01.2018

1 Bióloga. Especialista. Fiscal Ambiental-Prefeitura Municipal de Cananéia. Cananéia/SP. Email: anap_maistro@hotmail.com

2 Engenheiro Agrônomo. Doutor. Professor Assistente Doutor- UNESP. Registro/SP. Emailferraz@registro.unesp.br 


\section{INTRODUÇÃO}

Costa, Bezerra e Freire (2013) cita que no Brasil e no mundo a avaliação da percepção é feita para medir o grau de satisfação da população com a arborização urbana. Para entender a percepção de uma pessoa é preciso examinar sua herança genética, criação, trabalho, arredores físicos como a paisagem e o ambiente onde vive (TONETTI; BIONDI; LEITE, 2016). É comum a aplicação de questionários para se fazer a avaliação. Para Pena et al. (2016) renovar o ponto de vista sobre a percepção dos problemas sociais e as dificuldades ecológicos encontradas pelos cidadãos são tarefas importantes a serem realizadas.

Desde muito tempo, o homem vem trocando o meio rural pelo meio urbano. As cidades foram crescendo, na maioria das vezes de forma muito rápida e desordenada, sem um planejamento adequado de ocupação, provocando vários problemas que interferem sobremaneira na qualidade de vida do homem que vive na cidade (PIVETTA; SILVA FILHO, 2002). Segundo o último levantamento de dados do IBGE o Brasil apresentava cerca $80 \%$ de sua população vivendo nas cidades (IBGE, 2017). A urbanização desordenada ocasiona diversos problemas ambientais, incluindo modificações adversas no microclima e na paisagem, que afetam a qualidade de vida e a saúde da população. A arborização das vias públicas é uma estratégia utilizada para minimizar tais problemas (FARIA; MONTEIRO; FISCH, 2007).

A arborização urbana constitui um elemento de fundamental importância para a obtenção de elevada qualidade de vida da população. É definida como o conjunto de vegetação arbórea e arbustiva, natural ou cultivada, distribuída nas praças, parques, áreas com remanescentes florestais naturais, povoamentos florestais nativos ou exóticos, áreas ciliares e demais áreas públicas de uma cidade. Além da função paisagística, ela proporciona outros benefícios à população tais como: purificação do ar pela fixação de poeiras e gases tóxicos e pela reciclagem de gases através dos mecanismos fotossintéticos; melhoria do microclima da cidade, mantem a umidade do solo pela ação física das raízes, gera umidade no ar pela transpiração das folhas, promove sombra, evitando que os raios solares incidam diretamente sobre as pessoas; reduz a velocidade do vento, influência no balanço hídrico, favorecendo a infiltração da água no solo; abrigo à fauna, propiciando uma variedade maior de espécies, e o que influencia positivamente ao ambiente, pois propicia maior equilíbrio das cadeias alimentares e diminuição de pragas e agentes vetores de doenças e amortecimento de ruídos (ANDREATTA et al., 2011).

Segundo Tischer, Forte e Pedroso-de-Moraes (2014) áreas verdes se caracterizam por apresentarem e manterem um clima ameno nas áreas urbanas, o que promove a reciclagem de água, a retenção de água, a contenção de vento, permitindo a sobrevivência de várias espécies de aves e plantas. 
Os estudos que enfocam a percepção da população em relação ao meio ambiente devem ser utilizados como um instrumento que a administração municipal pode utilizar no planejamento e gestão de áreas verdes, atendendo a população através de políticas públicas, estabelecendo programas de educação ambiental e incentivando estudos acadêmicos na área (OLIVEIRA, 2005).

Com este trabalho, pretende-se inaugurar esse tipo de estudo no município de Cananéia para fornecer subsídios para o planejamento da arborização urbana e aplicação de medidas mitigadoras que possam melhorar a qualidade ambiental.

\section{MATERIAL E MÉTODOS}

Este estudo foi realizado em Cananéia, localizado no extremo sul do litoral do Estado

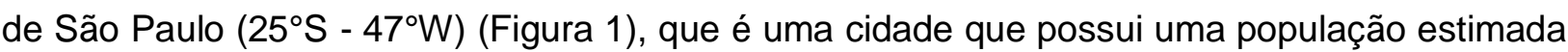
em 12.609 habitantes (IBGE, 2017). O número total dos entrevistados foi de 80 pessoas, correspondendo a aproximadamente a $0,7 \%$ da população do município, o que representa uma amostragem da população. Para determinar o tamanho da amostra foi tomada como variável de recorte a percepção se a cidade é bem arborizada ou não. Uma vez que não se conhecia, a priori, a essa porcentagem, admitiu-se que essa proporção se dividia igualmente entre dois grupos.

Dessa forma, assumindo-se um valor unilateral de $Z$ a $5 \%$ de probabilidade para um valor máximo de 10\%, estimou-se a amostra de 68 indivíduos, conforme (LWANGA e LEMESHOW, 1991). Para tal utilizou-se a aplicação de questionários semi-estruturados aos residentes da área urbana do município entre os meses de abril e maio de 2015. Para a coleta de dados foram selecionados oito bairros, entre eles estão Acaraú, Carijo, Centro, Rocio, Retiro das Caravelas, Vila Cabana, Morro São João e Vigoreli, onde realizou-se a aplicação de um questionário com dez perguntas a um residente por domicílio, contendo questões abertas e objetivas com o intuito de tentar detectar os anseios e opiniões dos munícipes sobre a arborização urbana. Estes bairros, são periféricos e centrais no município, porém todos localizados na ilha principal de Cananéia, ou seja, bairros localizados na zona urbana e próximos ao centro da cidade. Os mesmos também foram selecionados por representarem a maior fatia populacional do município. O critério de escolha dos entrevistados foi essencialmente por serem moradores das áreas estabelecidas previamente e terem idade mínima de 18 anos. O emprego dos questionários foi estabelecido por amostragem sistemática, onde se escolhia uma rua do bairro, e a cada cinco residências aplicava-se um questionário, conforme a metodologia adotada por Brun, Longhi e Brun (2009). As questões abordadas no 
questionário foram: gênero, faixa etária, número de moradores na residência, grau de escolaridade, grau de arborização na rua (que consiste numa escala que avalia as vias públicas em muito arborizadas, pouco arborizadas e razoavelmente arborizadas) vantagens e desvantagens apresentadas pela arborização, a forma de encaminhamento de reclamações a órgãos públicos e privados, responsabilidade da arborização urbana, forma de colaboração e melhoria da arborização, disponibilidade de plantar uma árvore na calçada e qual espécie escolhida, contribuição financeira para implantação da arborização na rua e a presença de árvores no quintal. Posteriormente, os dados coletados foram processados em planilha do programa Microsoft Excel 2007 e os resultados apresentados em porcentagem e gráficos.

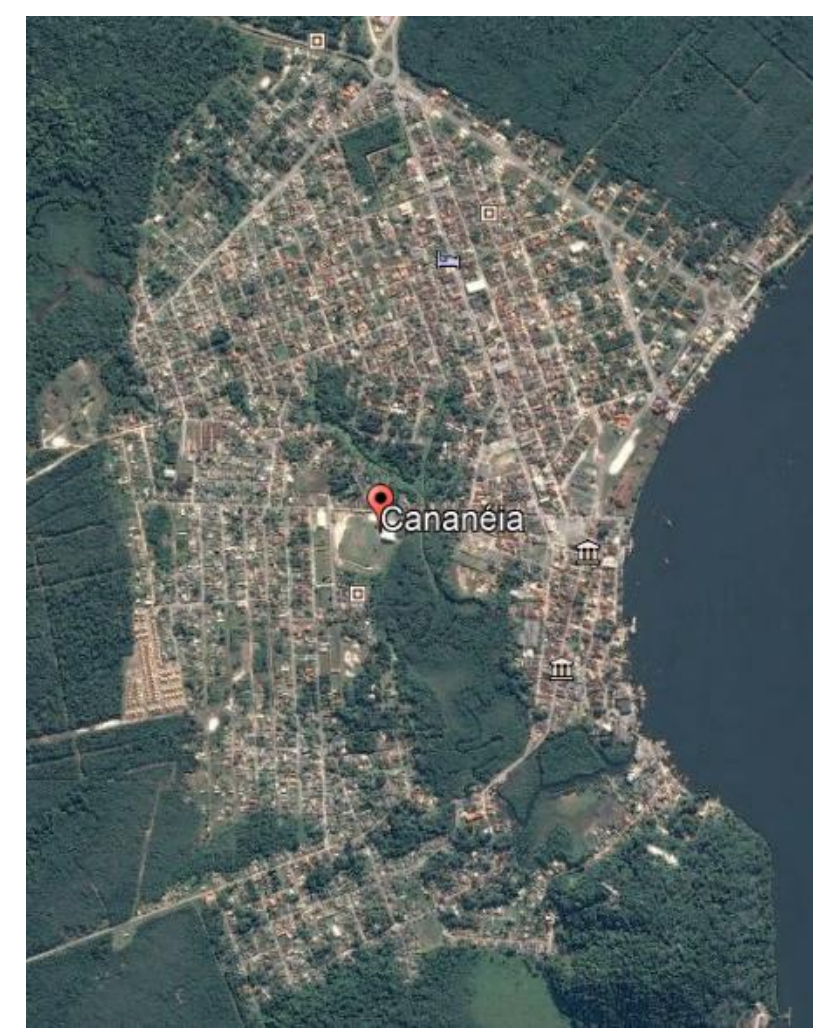

Figura 1. Ilha principal do município de Cananéia-SP (Imagem: Google Earth, 2017)

Figure 1. Main island of the municipality of Cananéia-SP (Image: Google Earth, 2017)

\section{RESULTADOS E DISCUSSÃO}

\section{Perfil da população estudada}

A partir dos resultados coletados pelo questionário aplicado a população, obteve-se informações a respeito da opinião dos munícipes referente a arborização urbana de Cananéia - SP cujo perfil social encontra-se na Tabela 1. 
Tabela 1.Perfil social dos entrevistados residentes no Município de Cananéia - SP

Table 1. Social profile of residents in the municipality of Cananéia - SP

\begin{tabular}{lc}
\hline \multicolumn{1}{c}{ Variáveis } & $\%$ \\
\hline Gênero & 57,5 \\
Feminino & 42,5 \\
Masculino & \\
\hline Faixa etária & 27,5 \\
Entre 18 e 30 anos & 36,3 \\
Entre 31 e 40 anos & 15 \\
Entre 41 e 50 anos & 15 \\
Entre 51 e 60 anos & 6,3 \\
Acima de 60 anos & \\
\hline Número de moradores por residência & 15 \\
Apenas 1 & 48,8 \\
Entre 2 e 3 & 32,5 \\
Entre 4 e 5 & 3,8 \\
Acima de 6 & \\
\hline Escolaridade & 2,5 \\
Ensino Fundamental Incompleto & 21,3 \\
Ensino Fundamental Completo & 10 \\
Ensino Médio Incompleto & 40 \\
Ensino Médio Completo & 8,8 \\
Ensino Superior Incompleto & 17,5 \\
Ensino Superior Completo &
\end{tabular}

A amostra foi composta por $57,5 \%$ de indivíduos do gênero feminino e $42,5 \%$ do gênero masculino, cuja faixa etária da maioria variou entre 31 e 40 anos (36,3\%). Um número de 2 a 3 moradores foi verificado na maioria das residências visitadas nos bairros do município $(48,8 \%)$. Quanto ao grau de escolaridade dos participantes verificou-se que $21,3 \%$ tinham ensino fundamental completo, 40\% com ensino médio completo e 17,5\% possuíam ensino superior completo. As porcentagens de 2,5\%, 8,8\% e 10\% foram encontradas para os entrevistados que não completaram o ensino fundamental, superior e médio, respectivamente. Notou-se que a escolaridade dos entrevistados é bastante variável, fato também observado por (SILVA; BATISTA; BATISTA, 2015).

As variáveis apresentadas serviram como parâmetro de representatividade da população, assim, as diversas camadas da população foram representadas neste estudo. Oliveira et al. (2017) afirmam que o estudo da percepção ambiental da população é fundamental para a gestão sustentável das cidades. 


\section{Percepção da população}

Quando instigados a atribuir uma classificação sobre o grau da arborização urbana utilizando as classes "muito", "razoavelmente" e "pouco arborizada", os entrevistados após sentirem o ambiente onde estavam inseridos responderam o questionário com a classe "razoavelmente arborizada" em 50\% das respostas, enquanto que as classes "muito arborizada" e "pouco arborizada" foram anotadas em 12,5 e $37,5 \%$ das respostas, respectivamente (Figura 2). É interessante ressaltar que a maioria da população percebe a carência de árvores no perímetro urbano de Cananéia - SP. Segundo Rodrigues et al. (2010), este tipo de avaliação tende a ser subjetiva dependendo em grande parte da maior ou menor vivência do morador no local, pelo fato que muitos tendem a avaliar a arborização de sua rua ou até mesmo a que se encontra em frente à sua casa. Em Curitiba -PR os usuários de áreas verdes se sentem atraídos não só pelas árvores das praças, mas principalmente pela função social que estes lugares exercem (VIEZZER et al., 2016). Avaliar a percepção que os moradores têm sobre a arborização urbana é tarefa que ajuda no combate da desigualdade social e no desenvolvimento urbano.

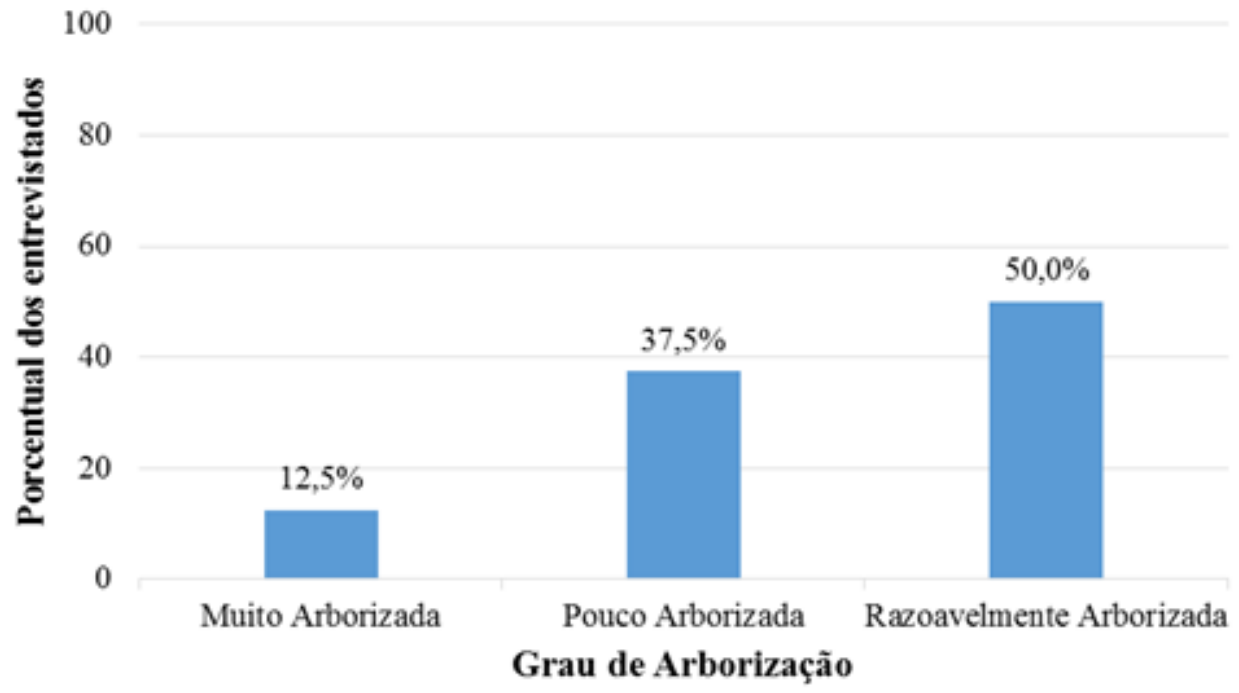

Figura 2. Percepção dos moradores de Cananéia-SP referente a arborização urbana Figure 2. Perception of the residents of Cananéia-SP referring to urban afforestation

Entre as vantagens da arborização apontadas pela população, nota-se que a maioria observa os benefícios na melhoria da qualidade do microclima urbano, onde $47,5 \%$ indicaram como vantagem a produção de sombra, 17,5\% apontaram a redução de calor e 7,5\% a melhoria da qualidade do ar, como pode ser observado na Figura 3. Estas características se justificam pela ocorrência de altas temperaturas durante a verão, as quais levam a população 
buscar diferentes meios que proporcionem maior conforto térmico. Em pesquisa realizada por HO et al. (2015) 61\% da população acreditava que a arborização urbana contribui para a redução da poluição atmosférica, 19\% para manter a resfrescância do ambiente, 16\% para a redução do impacto da chuva, com $6 \%$ que acreditavam que as árvores urbanas amenizavam a poluição sonora, geravam sombra e apenas $3 \%$ confirmavam que as árvores deixavam o ambiente mais bonito.

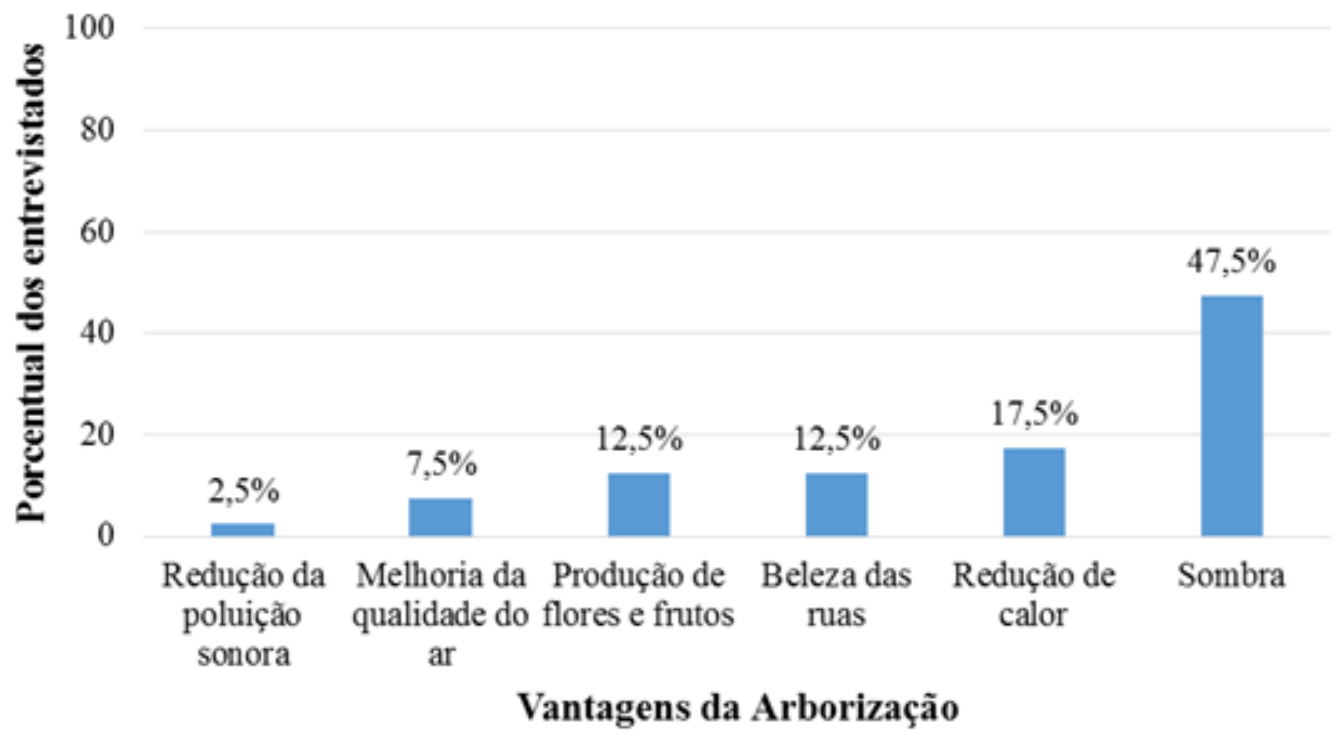

Figura 3. Vantagens apresentada na arborização urbana observada pela população de Cananéia-SP Figure 3. Advantages presented in the urban afforestation observed by the population of Cananéia-SP

Segundo Santos e Teixeira (2001), embora a vegetação não possa controlar totalmente as condições de desconforto, ela pode, eficientemente, abrandar a sua intensidade. Já as vantagens como, produção de flores e frutos, beleza das ruas e redução da poluição sonora foram escolhidas pelos entrevistados em 12,5\%, 12,5\% e 2,5\% respectivamente, características estas que, segundo Roppa et al. (2007), demonstram que com a implantação da arborização houve a valorização imobiliária, a atração de fauna e flora, além da melhoria na qualidade de vida.

A respeito das desvantagens da arborização urbana apontadas pelos moradores destacaram-se: problemas com rede elétrica ou telefônica $(33,7 \%)$, problemas na calçada $(23,8 \%)$ e sujeira nas ruas e calçadas $(21,3 \%)$, conforme evidenciado na Figura 4. 


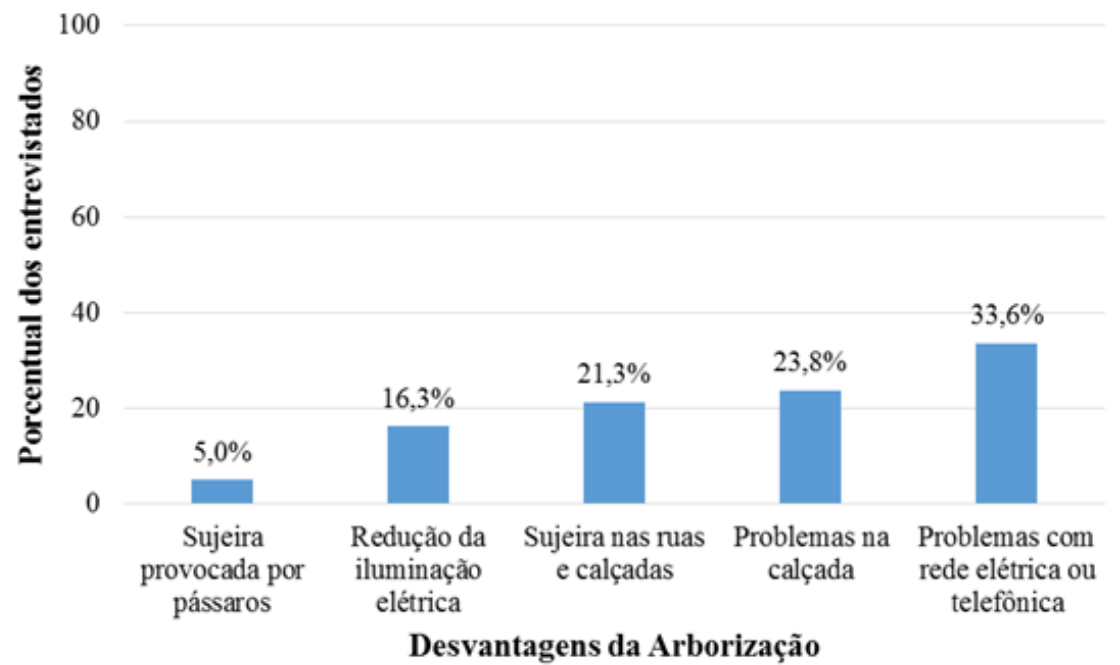

Figura 4. Desvantagens apresentadas na arborização observada pela população de Cananéia-SP Figure 4. Disadvantages presented in the afforestation observed by the population of Cananéia-SP

As características como a redução da iluminação elétrica e a sujeira provocada por pássaros foram mencionadas em 16,3\% e 5\% das respostas, respectivamente. Quando indagados sobre a quem encaminhar as reclamações referentes a arborização urbana, $50 \%$ dos entrevistados responderam corretamente que procurariam a Prefeitura, $5 \%$ citaram a companhia de energia elétrica ou telefônica e $45 \%$ encaminhariam as reclamações para os dois órgãos (Figura 5). Tais competências devem ser explícitas nos planos diretores e nas leis do uso e ocupação do solo. Por outro lado, nota-se que ainda há uma incerteza sobre a qual órgão recorrer em casos onde é necessária a poda. Para Bobrowski (2016) faltam critérios sobre o melhor manejo a ser feito em uma árvore, mesmo existindo avaliações visuais como parte do manejo do processo de gestão da arborização urbana.

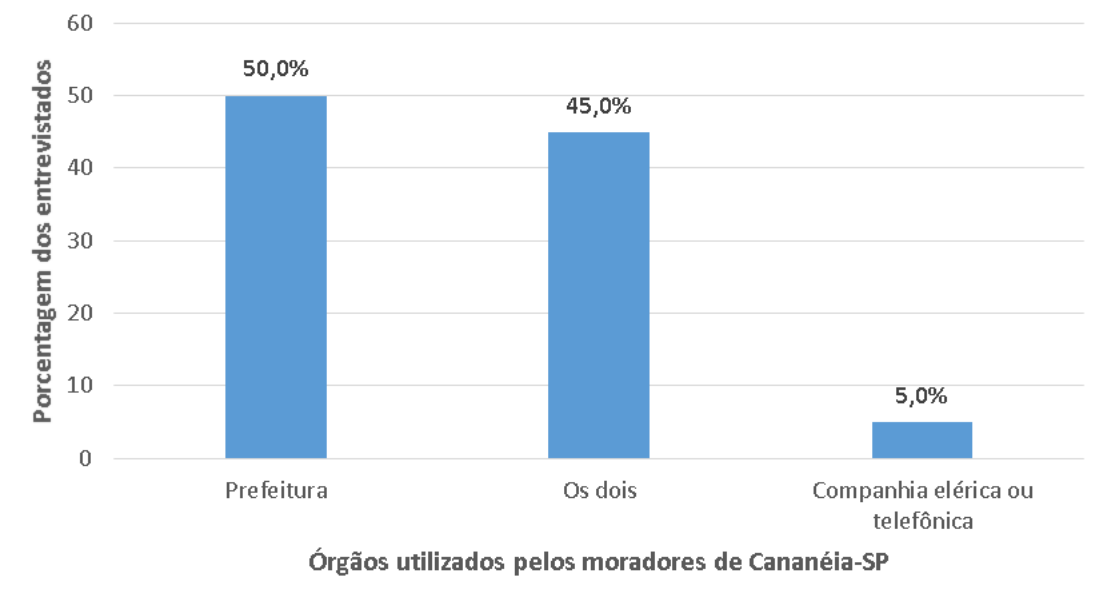

Figura 5. Órgãos utilizados pelos moradores de Cananéia-SP para encaminhamento de reclamações referentes a arborização urbana

Figure 5. Organs used by residents of Cananéia-SP to submit claims related to urban afforestation 
A maioria $(66,3 \%)$ dos moradores considerou a Prefeitura como a responsável pela arborização urbana e 33,8\% acredita que a responsabilidade deve ser compartilhada entre a prefeitura e os próprios moradores.

O relacionamento entre a população residente e a arborização urbana da cidade de Cananéia foi caracterizado mediante a pergunta de como os munícipes colaboram com a arborização, onde 50\% declararam que não danificam, 23,8\% colaboram plantando árvores, $20 \%$ realizam poda e manutenção e 6,3\% disseram que nada fazem (Figura 6), porém a segunda e terceira forma de colaboração repercute na maioria das vezes em equívocos como a implantação de espécies inadequadas, que danificam calçadas e a rede aérea ou a realização de poda de forma incorreta ou desnecessária. Pivetta e Silva Filho (2002) citam que em muitos casos nem é indicado plantio de árvores.

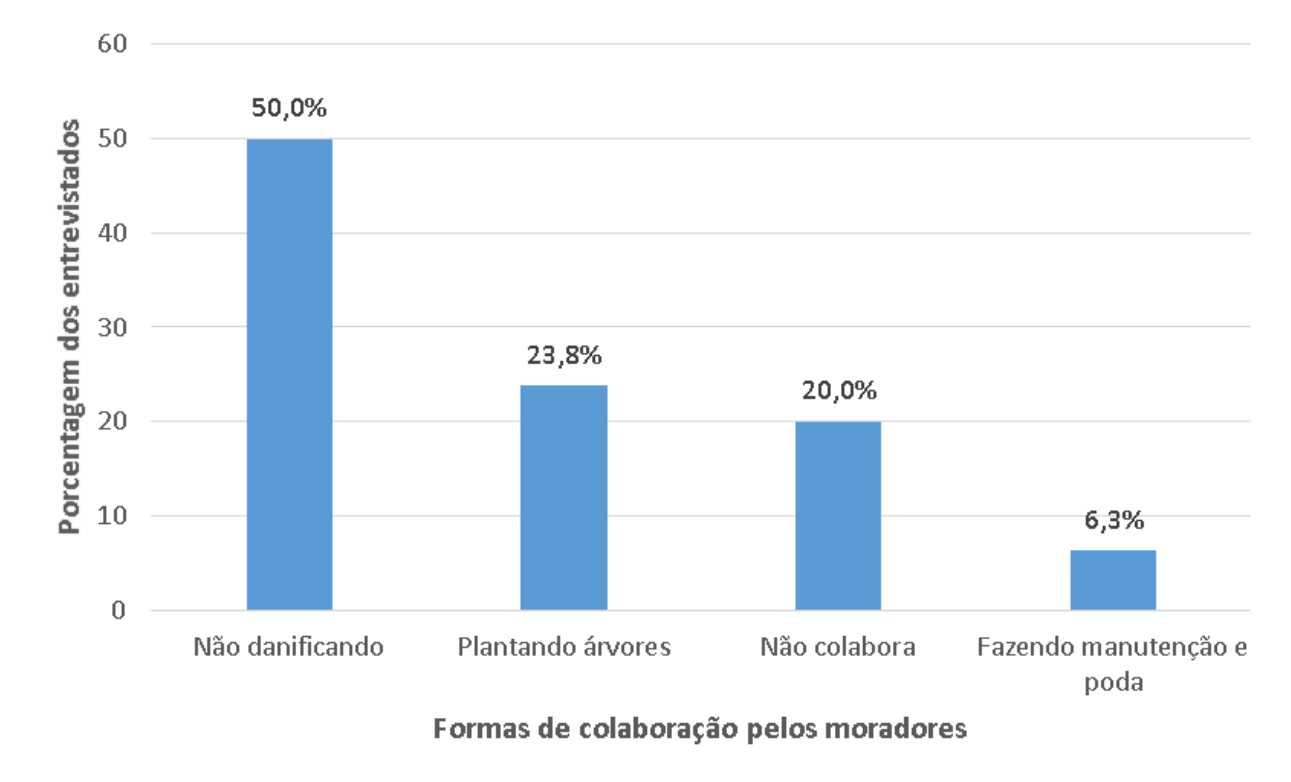

Figura 6. Formas de colaboração com a arborização urbana realizadas pelos moradores de Cananéia-SP

Figure 6. Forms of collaboration with the urban afforestation carried out by the residents of Cananéia$\mathrm{SP}$

O presente estudo também buscou identificar as opiniões dos entrevistados sobre o que poderia ser feito para melhorar a arborização do município. A maioria dos moradores afirmou que o plantio de árvores é uma das medidas que deve ser tomada para melhorar a arborização. Outras medidas também apareceram com frequência nas respostas dos entrevistados, como realizar a manutenção e poda corretas das árvores existentes nas ruas, promover campanhas de conscientização ambiental no que diz respeito a importância da proteção das árvores e até mesmo a criação de um sistema de multa para quem danificar e/ou cortar as árvores sem a prévia autorização dos órgãos competentes (Figura 7). 


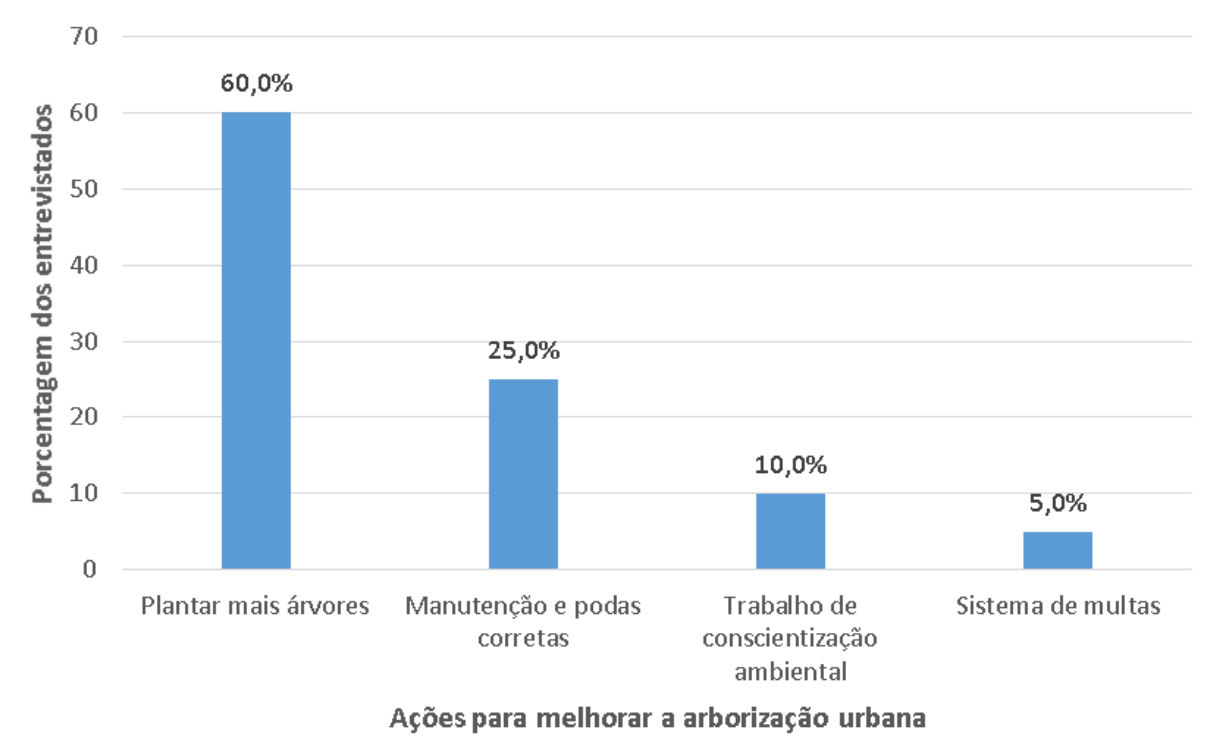

Figura 7. Ações que deveriam ser realizadas para melhorar a arborização urbana segundo a opinião dos moradores de Cananéia - SP

Figure 7. Actions that should be carried out to improve urban afforestation according to the opinion of the residents of Cananéia - SP

Com base na indicação das espécies preferidas para serem implantadas nas ruas, observou-se conforme a Figura 8, que 27,5\% dos moradores indicaram o plantio de árvores, outros $25 \%$ apontaram a preferência por árvores frutíferas e $18 \%$ por árvores floríferas. Estes dados coincidem com os apontados pelos frequentadores do estudo de Zardin et al. (2017) que sugerem para a melhoria no paisagismo o plantio de árvores frutíferas e nativas. Gonçalves, Coral e Siqueira et al. (2017) afirmam que a escolha das espécies no paisagismo deve prevalecer as de ocorrência regional, visto que a utilização de plantas nativas auxilia na preservação da flora local e reforça a identidade regional.

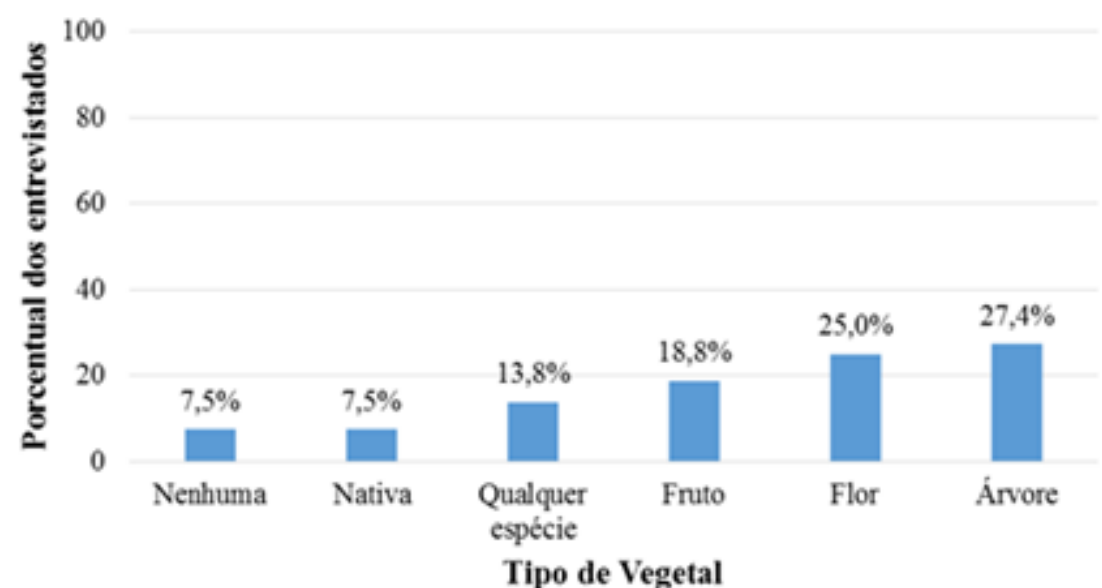

Figura 8. Preferências dos moradores de Cananéia-SP quanto ao tipo de vegetal a ser plantado na arborização urbana do município

Figure 8. Preferences of the residents of Cananéia-SP as to the vegetal type to be planted in the urban afforestation of the municipality 
Já 13,8\% dos entrevistados não possuem preferência por espécie de árvores, enquanto que 7,5\% citaram árvores nativas e 7,5\% optaram por não plantar árvore na rua. $\mathrm{A}$ combinação das respostas confirma a necessidade da melhoria na arborização urbana, minimizando os efeitos no clima e aumentando a qualidade do ar.

Quando foi perguntado se o morador plantaria uma árvore na calçada, caso uma muda fosse doada, $48,8 \%$ responderam positivamente, enquanto que $20 \%$ não plantariam alegando que a residência é alugada, 16,3\% atribuíram ao risco de a árvore encostar-se à fiação elétrica e $15 \%$ dos entrevistados apontou que seria inviável pelo fato da calçada ser estreita, característica esta frequentemente presente nas ruas do município devido ao histórico de colonização (Figura 9). Soares et al. (2017), arborizar não significa plantar árvores aleatoriamente em qualquer lugar, mas seguir normas e diretrizes legais; já existem árvores para cada local. Graciano-Silva, Cardoso e Tonello et. al., (2014) concluíram que a falta de seleção de espécies compatíveis com o local de plantio, resultam em copas se chocando com a fiação elétrica.

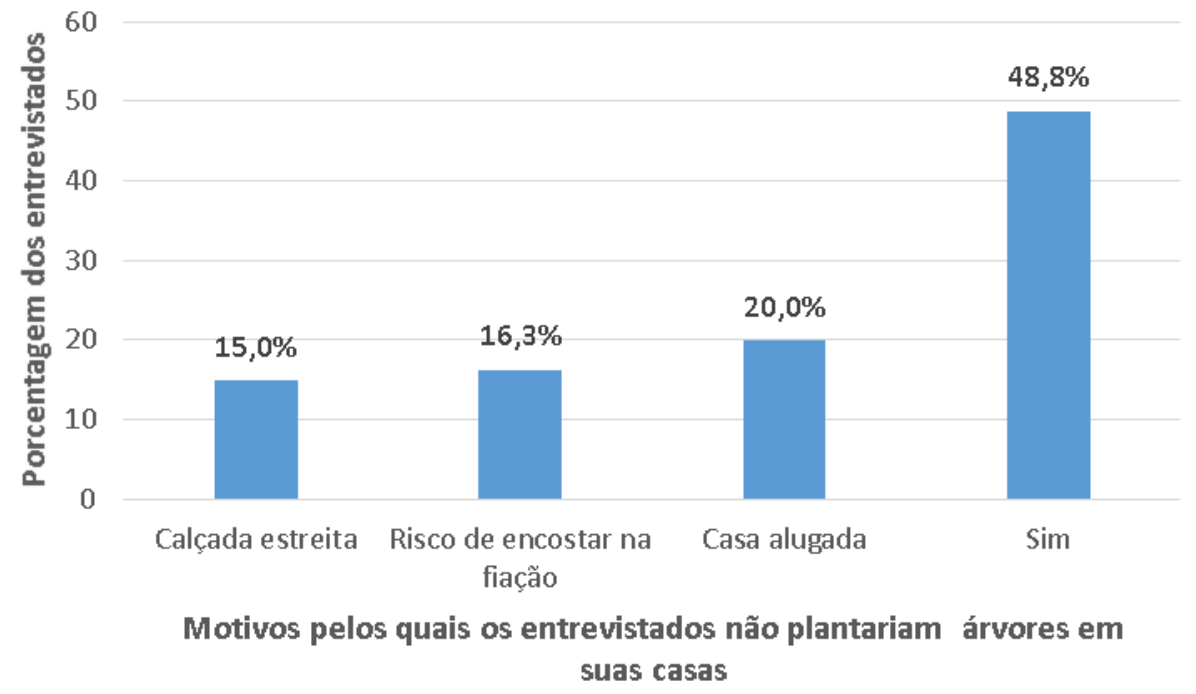

Figura 9. Motivos pelos quais os entrevistados não plantariam árvores em sua própria calçada Figure 9. Reasons why respondents would not plant trees on their own sidewalk

E por fim, os entrevistados foram consultados sobre a possibilidade de contribuir financeiramente para a manutenção da arborização urbana, destes 93,8\% afirmaram estar dispostos a contribuir, sendo que os valores variaram de $R \$ 1,00$ a $R \$ 10,00$, entretanto $6,2 \%$ responderam que não contribuiriam (Figura 10). Para Roppa et al. (2007), medir o quanto vale a arborização é muito difícil, mas a ação de cada indivíduo poderá ajudar a realizar muito pela arborização. 


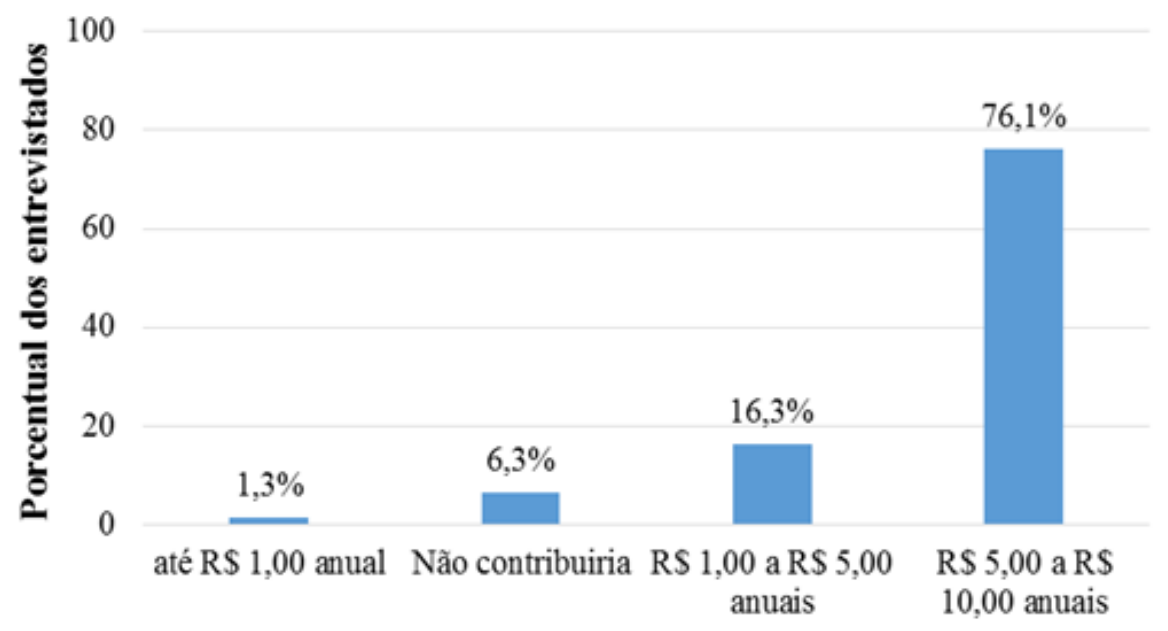

Contribuição Financeira

Figura 10. Possibilidade de contribuição financeira para a manutenção da arborização segundo os moradores de Cananéia-SP

Figure 10. Possibility of financial contribution for the maintenance of afforestation according to the residents of Cananéia-SP

\section{CONCLUSÕES}

$\mathrm{Na}$ percepção dos moradores de Cananéia existe uma carência de arborização urbana, visto que a maioria classificou a arborização das ruas como "razoável" e quando indagados sobre o que poderia ser feito para melhorar a arborização urbana, a maioria indicou a realização do plantio de mais árvores nas ruas da cidade. Foi possível identificar que as consequências da falta de planejamento relacionado a arborização urbana, são observadas pelos moradores, sobretudo pelo plantio de espécies inadequadas em locais 


\section{REFERÊNCIAS}

ANDREATTA, T. R.; BACKES, F. A. A. L.; BELLÉ, R. A.; NEUHAUS, M.; GIRARDI, L. B.; SCHWAB, N. T.; BRANDÃO, B. S. Análise da arborização no contexto urbano de avenidas de Santa Maria, RS. Revista da Sociedade Brasileira de Arborização Urbana, Piracicaba, v. 6, n. 1, p. 36-50, 2011.

BOBROWSKI, R. Problems and distinctions among methods for assessment of the general condition of urban tress. Revista da Sociedade Brasileira de Arborização Urbana, Piracicaba, v. 11, n. 2, p. 1-11, 2016.

BRUN, F. G. K.; LONGHI, S. J.; BRUN, E. J. Estudo da percepção da população de vilas do bairro Camobi, Santa Maria - RS sobre a arborização urbana. Revista de Estudos Ambientais, Piracicaba, v. 11, n. 1, p. 6-21, 2009.

COSTA, C. G. F.; BEZERRA, R. F.; FREIRE, G. S. Avaliação da percepção da arborização urbana em Fortaleza. Revista da Sociedade Brasileira de Arborização Úrbana, Piracicaba, v. 8, n. 4 , p. $73-88,2013$.

FARIA, J. L. G.; MONTEIRO, E. A.; FISCH, S. T. V. Arborização de vias públicas do município de Jacareí-SP. Revista da Sociedade Brasileira de Arborização Urbana, Piracicaba, v. 2, n. 4 , p. 20-33, 2007.

GRACIANO-SILVA, T.; CARDOSO-LEITE. E TONELLO, K. C. INVENTÁRIO DA ARBORIZAÇÃO URBANA NO MUNICÍPIO DE ARAÇOIABA DA SERRA, SP. Revista Brasileira de Arborização Urbana, Piracicaba, v.9, n.4, p 151-169, 2014.

GONÇALVES, W. G; CORAL, D. J. E. SIQUEIRA, M. V. B. M. Caracterização da arborização urbana no bairro centro do município de IBITINGA/SP. Revista da Sociedade Brasileira de Arborização Urbana, Piracicaba, v.12, n.3, p. 66-79, 2017.

LWANGA, S.K.; LEMESHOW, S. Sample size determination in health studies: a practical manual. Geneva: World Health Organization; 1991.

HO, T. L.; KOVALSYKI, B.; ZAMPRONI, K.; BIONDI, D. Percepção dos moradores sobre a arborização de ruas da região central de Mandirituba/PR. Revista da Sociedade Brasileira de Arborização Urbana, Piracicaba, v. 10, n. 3, p. 14-23, 2015.

INSTITUTO BRASILEIRO DE GEOGRAFIA E ESTATÍSTICAS (IBGE). Sinópse do Censo demográfico 201. Disponível em: https://cidades.ibge.gov.br/brasil/sp/cananeia/panorama> Acesso em: 27 out. 2017.

OLIVEIRA, V. P.; DIAS, J. G. S.; RIBEIRO, A. T.; OLIVEIRA, L. B. S.; MARIANA DE OLIVEIRA MARIANO, M. O. e PINTO, D. S. A percepção da população sobre arborização em um conjunto habitacional no município de Paragominas-PA. Revista da Sociedade Brasileira de Arborização Urbana, Piracicaba, v.12, n.3, p. 27-36, 2017

OLIVEIRA, E. Z. A percepção ambiental da arborização urbana dos usuários da avenida Afonso Pena entre as ruas Calógeras e Ceará da cidade de Campo Grande - MS. Campo Grande. Campo Grande, 2005. 125 f. Dissertação (Mestrado em Meio Ambiente e Desenvolvimento Regional), Universidade Anhanguera de Campo Grande, Mato Grosso do Sul, 2005. 
PENA, J. C.; MAGALHÃES, D. M.; MOURA, A. C. M.; YOUNG, R. J.; RODRIGUES, M. The green infrastructure of a highly-urbanized neotropical city: the role of the urban vegetation in preserving native biodiversity. Revista da Sociedade Brasileira de Arborização Urbana, Piracicaba, v. 11, n. 4, p. 66-78, 2016.

OLIVEIRA, V. P.; DIAS, J. G. S.; RIBEIRO, A. T.; OLIVEIRAS, L. B. S.; MARIANO, M. O. E PINTO, D. S. A percepção da população sobre arborização em um conjunto habitacional no município de Paragominas-PA. Revista Brasileira de Arborização Urbana, Piracicaba, v.12, n.3, p. 27-36, 2017.

PIVETTA, K. F. L.; SILVA FILHO, D. F. Arborização urbana. Jaboticabal, 2002. 69f. ApostilaFaculdade de Ciências Agrárias e Veterinárias, Jaboticabal, São Paulo, 2002.

RODRIGUES, T. D.; MALAFAIA, G.; QUEIROZ, S. E. E.; RODRIGUES, A. S. L. Percepção sobre arborização urbana de moradores em três áreas de Pires do Rio - Goiás. Revista de Estudos Ambientais, Blumenau, v. 12, n. 2, p. 47-61, 2010.

ROPPA, C.; FALKENBERG, J. R.; STANGERLIN, D. M.; BRUN, F. G. K.; BRUN, E. J.; LONGHI, S. J. Diagnóstico da percepção dos moradores sobre a arborização urbana na vila estação colônia - bairro Camobi, Santa Maria - RS. Revista da Sociedade Brasileira de Arborização Urbana, Piracicaba, v. 2, n. 2, p. 11-30, 2007.

SANTOS, N. R. Z. dos; TEIXEIRA, I. F. Arborização de Vias Públicas: Ambiente X Vegetação. Santa Cruz do Sul: Instituição Souza Cruz, 2001. 135p.

SILVA, D. A.; BATISTA, D. B.; BATISTA, A.C. Percepção da população quanto a arborização com Mangifera indica I. (mangueira) nas ruas de Belém - PA. Revista da Sociedade Brasileira de Arborização Urbana, Piracicaba, v. 10, n. 1, p. 1-18, 2015.

SOARES, A. M. J.; ALVES, R. L. E TARGINO, E. N. M. A. Acessibilidade na arborização urbana: percepção de deficientes visuais sobre a mobilidade em espaços públicos arborizados. Revista Brasileira de Arborização Urbana, Piracicaba, v.12, n.3, p. 51-65, 2017

TISCHER, J. C.; FORTE, A. R.; PEDROSO-DE-MORAES, C. Análise qualiquantitativa de indivíduos arbóreos das praças centrais do município de Leme, SP. Revista da Sociedade Brasileira de Arborização Urbana, Piracicaba, v. 9, n. 3, p. 49-64, 2014.

TONETTI, A. M.; BIONDI, D.; LEITE, J. C. M. Perfil dos usuários de áreas verdes de Curitiba e a sua percepção sobre a capivara (Hydrochoerus hydrochaeris L.). Revista da Sociedade Brasileira de Arborização Urbana, Piracicaba, v. 11, n. 4, p. 47-65, 2016.

VIEZZER, J.; BIONDI, D.; BATISTA, A. C.; BRANDT, B. Perfil dos usuários e sua percepção dos elementos de composição paisagística das praças de Curitiba-PR. Revista da Sociedade Brasileira de Arborização Urbana, Piracicaba, v. 11, n. 3, p. 1-16, 2016.

ZARDIN, M. C.; OLIVEIRA, J. D.; ARTHUSO, J. P. E BIONDI, D. Perfil e percepção dos frequentadores do parque municipal São Lourenço de Curitiba - PR. Revista Brasileira de Arborização Urbana, Piracicaba, v.12, n.3, p. 37-50, 2017. 